\title{
CONTRIBUCION AL ESTUDIO DE LOS HYPHOMYCETES DE ESPAÑA. IV
}

\author{
J. GUARRO *; M. ${ }^{a}$ A. CALVO * \& E. VICENTE**
}

\section{RESUMEN :}

En el intento de caracterizar los Hyphomycetes pertenecientes a la flora fúngica de nuestro país, se describen siete especies aisladas de diversos sustratos. Dichas especies son: Babusakala olivaceonigra, Curvularia harveyi, Oedocephalum nicotianae, Exophiala brunnea, Helminthosporium velutinum, Alternaria longipes, y Zygosporium gibbum.

\section{SUMMARY:}

Atiempting the caracterization of the Hyphomycetes pertaining the fungous flora of Spain, seven species isolated from several substrata were described: Babusakala olivaceonigra, Curvularia barveyi, Oedocephalum nicotianae, Exophiala brunnea, Helminthosporium velutinum, Alternaria longipes y Zygosporium gibbum.

Bahusakala olivaceonigra (Berk. \& Br.) Subram., J. Indian bot. Soc., 37: 61-63 (1958).

Septonema olivaceo-nigrum Berk. \& Br. J. Linn. soc. 14: 90 (1873).

En agar extracto de malta al 2\% forma colonias de color marronáceo oscuro. Aspecto pulverulento. Micelio superficial. Conidióforo semimacronematoso, mononematoso, irregularmente ramificado. Las paredes del conidióforo son lisas y oscuras. El diámetro del conidióforo es de 3 a 5 u. Células conidiógenas integradas, intercalares y terminales, fragmentándose y formando artroconidios. Conidios en cadenas simples, aparecen conidios con una sola septa, algunos con 2 a 5 septas, presentando estrías rugosas características, cilíndricos y truncados en los extremos, midiendo de 5 a 22 u. de longitud por 3,8 a 5,3 u. de grosor.

$\left({ }^{*}\right)$ Cátedra de Microbiología. Facuitad de Farmacia. Barcelona. 
Cepa aislada: F.F.B. 210; fue aislada de la atmósfera de Barcelona en el mes de Diciembre de 1977.

De este género se conocen dos o tres especies y entre los rasgos característicos que permiten diferenciarla del género Geotrichum, que también presenta artroconidios, destacan el aspecto no levaduriforme de sus colonias y la gran abundancia de micelio aéreo.

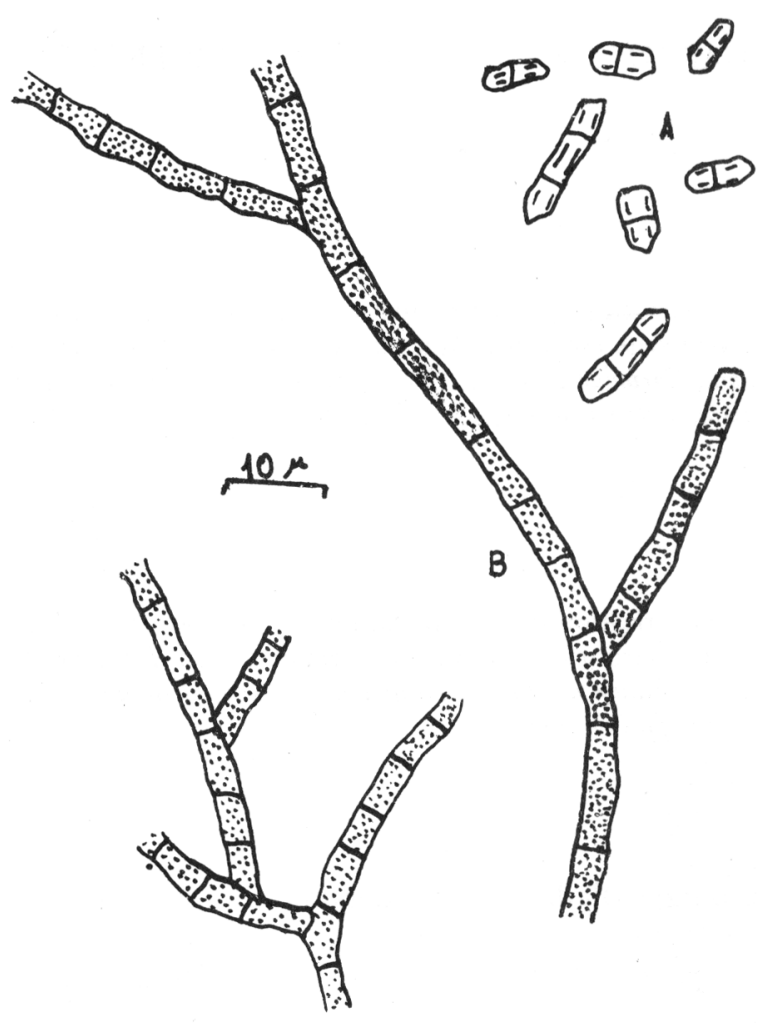

Fig. 1.-Babusakala olivaceonigra (Berk. \& Br.) Subram. A. Conidios; B. Conidióforos (x $1.000)$.

\section{Curvularia harveyi Shipton}

Las colonias en agar extracto de malta (fig. 2) al 2\% son de color marronáceo. Aspecto aterciopelado. Micelio sumergido. Reverso de color oscuro. No forma estroma. Conidióforos macronematosos, nudosos, rectos, de paredes marronáceas generalmente lisas. Conidios solitarios acropleurógenos, simples, normalmente rectos o ligeramente curvados, elipsoidales, de paredes oscuras con 3 ó 4 septas verdaderas y apéndice basal manifiesto. Miden 25-42 u. x 9,8-14,3 u. 
Células conidiógenas politétricas, integradas y con cicatrices típicas. Cepa aislada: F.F.B. 211; fue aislada de la atmósfera de Barcelona en el mes de febrero de 1977.

Podría ofrecer algún motivo de duda la clasificación de esta cepa como Curvularia harveyi ya que según Ellis (1971) tal especie posee predominantemente tres septas, sin embargo en esta estirpe las diferencias de porcentajes de conidios tri o tetraseptados no son significativas, pero por la forma de los conidios así como por su tamaño podemos considerarla como tal.

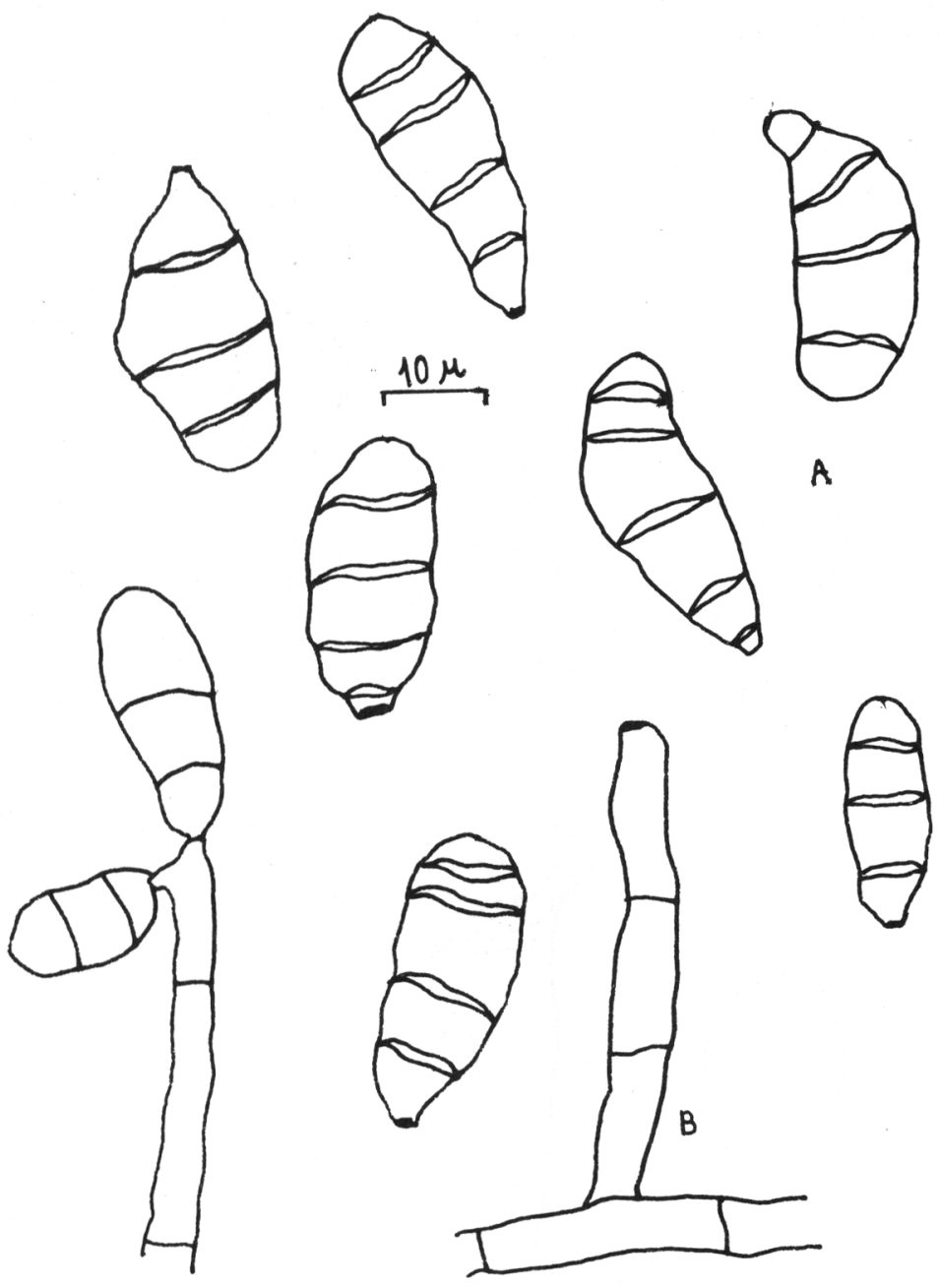

Fig. 2.-Curvularia harveyi Shipton. A. Conidios; B. Conidióforo (x 1.000). 
Oedocephalum nicotianae Oudem. Ned. Kruidk. Archief. Ser. 3,2: 906 (1903)

En agar extracto de malta al $2 \%$ las colonias presentan aspecto difuso con velocidad de crecimiento moderado. Esporulación abundante. Reverso incoloro. No poseen olor característico, ni pigmento difusible en el medio de cultivo. Tonalidades blanquecinas que con el tiempo pasan a amarillentas. Conidióforos macronematosos, mononematosos, hialinos, con septas. Son de paredes lisas o ligeramente rugosas. Miden de 60 a 80 u. de longitud por 8 a 12 u. de grosor. Vesículas de 16,8 a 18,9 u. por 11,9 a 18,9 u. Blastoconidios hialinos, con aspecto globoso o ligeramente elipsoidal, lisos, de crecimiento sincrónico, dejando la vesícula con aspecto denticulado después de separarse de ella.

Cepa aislada: F.F.B. 212; fue aislada de la atmósfera de Barcelona en el mes de enero de 1977.

Pertenece a la sección Glomerulosa establecida por Stalpers (1974). Especie íntimamente relacionada con $O$. glomerulosum de la que se diferencia por el tamaño de sus blastoconidios.
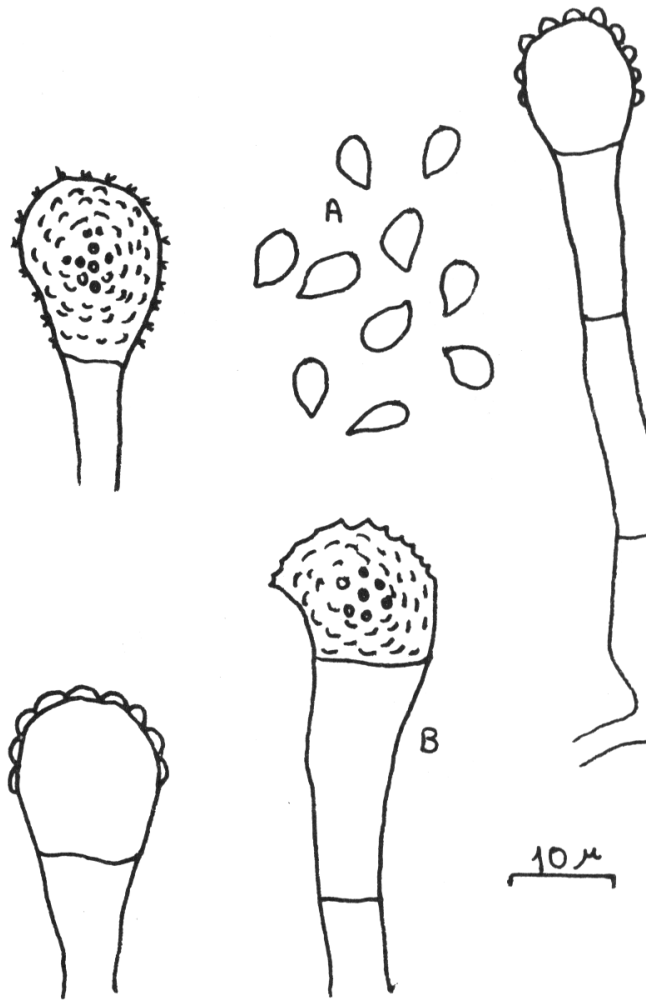

B
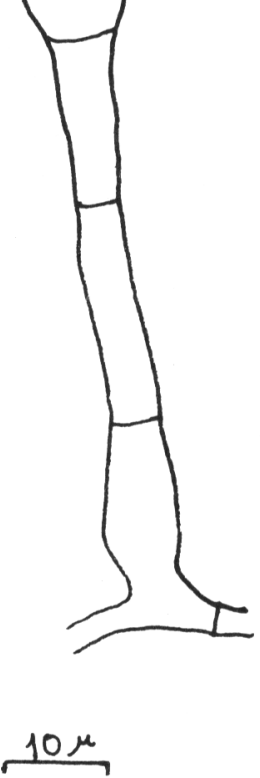

Fig. 3.-Oedocephalum nicotianae Oudem. A. Conidios; B. Conidióforos (x 1.000). 
Exophiala brunnea Papendorf. Trans. Brit. Mycol. Soc. 52: 483 (1969).

En agar extracto de malta al $2 \%$ las colonias presentan aspecto aterciopelado. Conidióforos semimacronematosos, mononematosos, lisos. Células conidiógenas monofiálicas y generalmente ampuliformes. Conidios agregados en masas gelatinosas, de forma mazuda, poseen de 0 a 1 septa, son de color marrón y miden de 1,8 a 2,7 u. x 4 a 9,8 u.

Cepa aislada: F.F.B. 72-2; aislada de almidón de trigo.

Han sido descritas tres especies pertenecientes al género Exophiala, (Arx, 1974) E. pisciphilus y E. salmonis causantes de micosis en peces y E. brunnea aislada del suelo. La distinción entre E. brunnea y E. salmonis basada en la forma y tamaño de los conidios.

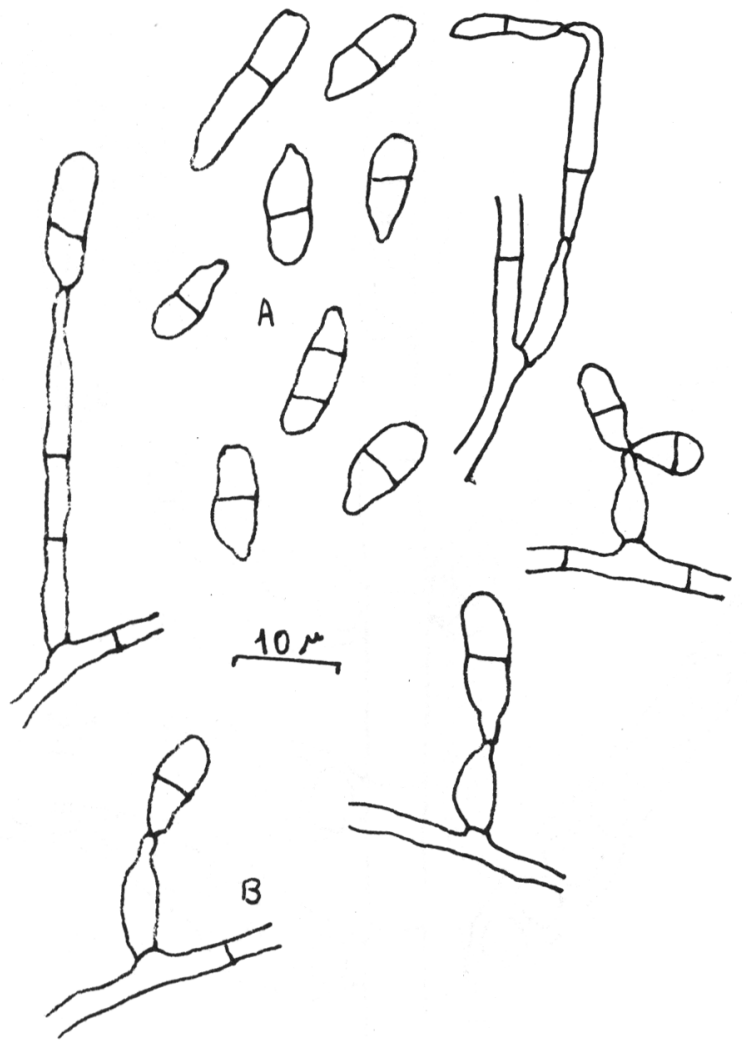

Fig. 4.-Exophiala brunnea. A. Conidios; B. Conidióforos (x 1.000). 
Helminthosporium velutinum Link ex Ficinus \& Schubert, Fl. Geg. Dresd. Krypt.: 283. (1823).

Las colonias en agar extracto de malta al $2 \%$ crecen rápidamente, son de color negruzco. En la parte central de las colonias poseen abundantes flóculos. Estroma oscuro. Conidióforos no ramificados, rectos de paredes oscuras, lisos. Células conidiógenas politétricas. Conidios solitarios, claviformes, que poseen pseudoseptos característicos de color oscuro. Los conidios miden por término medio 67 $\mathrm{x} 14,8$ u. Fue aislado en diversa ocasiones del almidón de trigo y patata y de la atmósfera de Barcelona.

Cepas aisladas: F.F.B. 213 (almidón de trigo), F.F.B 214, F.F.B. 218 (almidón de patata), F.F.B. 217 atmósfera de Barcelona.

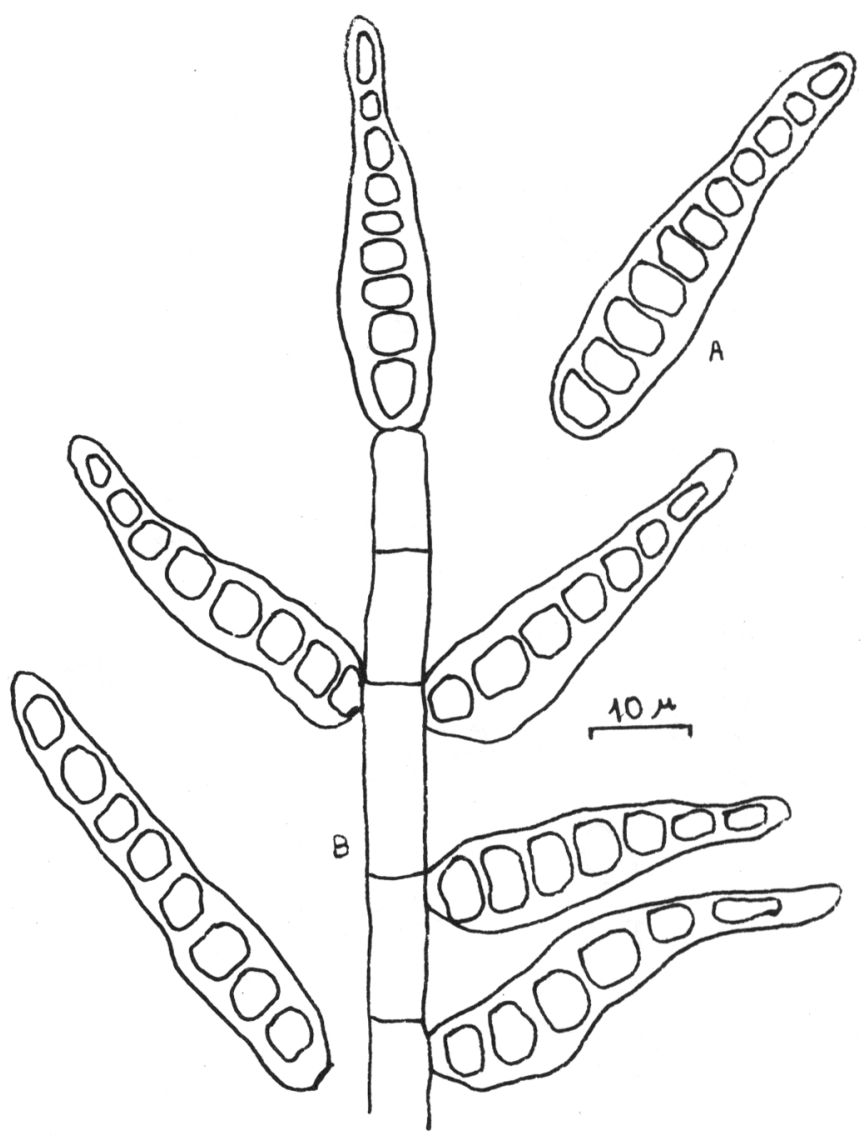

Fig. 5.- Helminthosporium velutinum Link ex Ficinus \& Schubert A. Conidios; B. Conidióforo (x 1.000). 
Alternaria longipes (Ellis \& Everth) Mason, Mycol. Pap. 2: 19 (1928), Macrosporium longipes Ellis \& Everth J. Mycol., 7: 134 (1892).

En agar extracto de malta al 5\%, medio descrito por Joly (1964) para el cultivo de las cepas del género Alternaria; las colonias presentan tonalidades marronáceas. Reverso de color marrón oscuro. Conidióforos macronematosos, mononematosos. Células conidiógenas, integradas. Conidióforos de longitud superior a las $80 \mathrm{u}$. y de 3 a 5 u. de grosor. Conidios generalmente solitarios, de aspecto mazudo y pare-
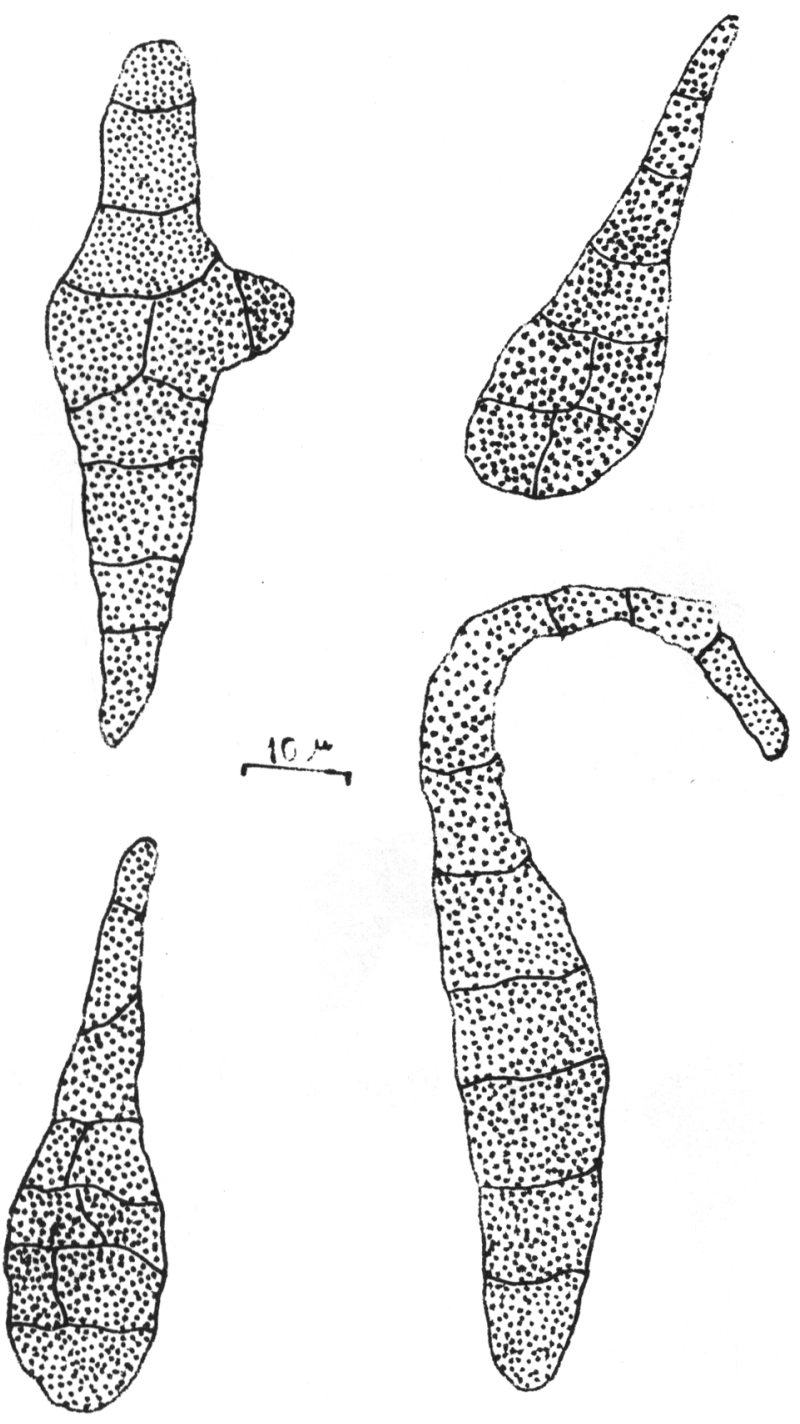

Fig. 6.-Alternaria longipes (Ellis \& Everth) Mason Conidios (x 1.000). 
des verrucosas, miden de 35 a 48 u. x 10-20u. Presentan de 3 a 7 septas transversas y algunas septas longitudinales, apéndice apical de coloración más clara. En su hábitat natural presenta características muy semejantes a las descritas. Fue aislada de hojas de Nicotiana tabacum.

Cepa aislada: F.F.B. 215, sobre hojas de Nicotiana tabacum.

Zygosporium gibbum (Sacc. Rouss. \& Bomm.) Hughes Can. J. Bot. 36: 825 (1958).

Zygosporium parasiticum (Grove) Bunting \& Mason, apud Mason En Mycol. Pap., 5, 137.

Colonias en agar extracto de malta al $2 \%$ presentando un aspecto flocoso, color grisáceo oscuro. Micelio superficial. Forma vesículas características falciformes

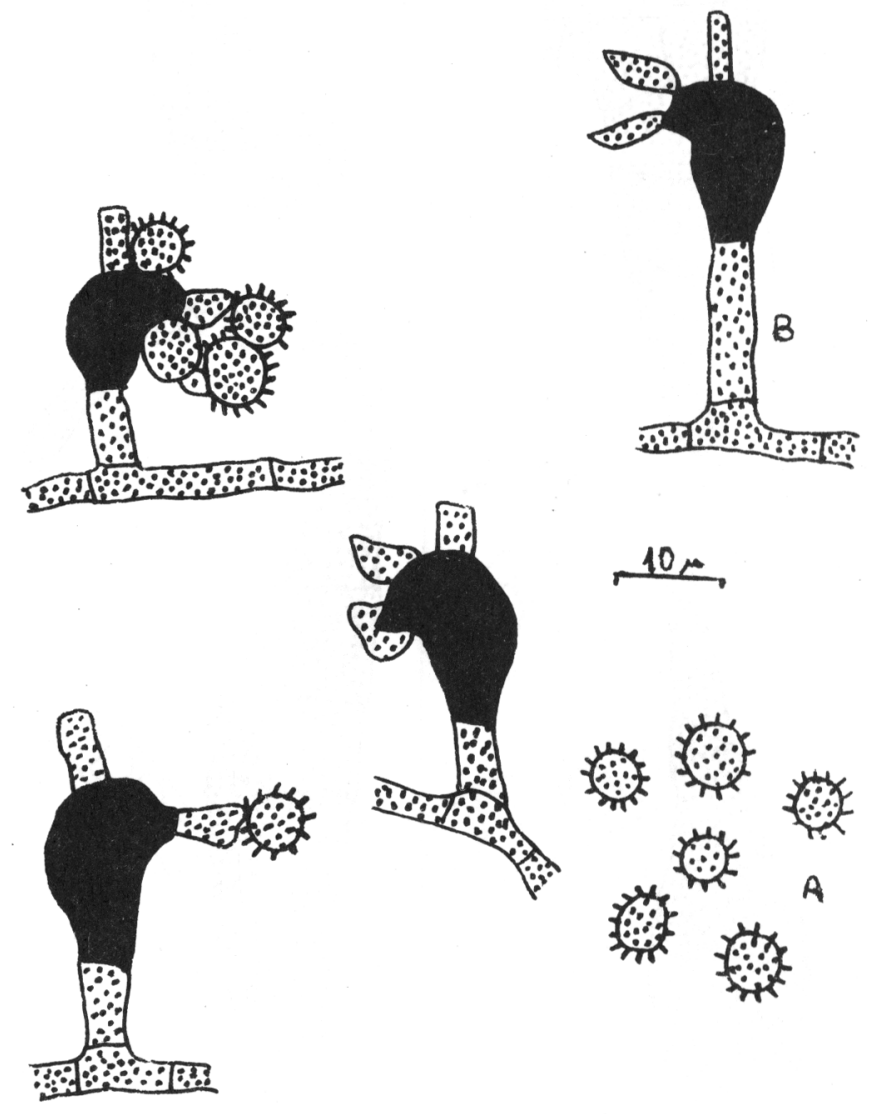

Fig. 7.-Zygosporium gibbum (Sacc., Rouss. \& Bomm.) Hughes A. Conidios; B. Conidióforos (x 1.000). 
de color oscuro que emergen del micelio a través de un corto pedúnculo. Células conidiógenas monoblásticas, determinadas, ampuliformes en el extremo apical de la vesícula. Conidios solitarios acrógenos, hialinos, esféricos, verrucosos, no septados que miden de 5,8 a 9 u. de diámetro.

Cepa aislada: F.F.B. 216; fue aislada en el mes de diciembre de 1977.

Esta especie difiere de la descrita por Ellis (1971) en el tamaño de sus conidios

ya que son ligeramente mayores, sin embargo por las restantes características podemos incluirlas en la mencionada especie y más si consideramos que la descripción original esta hecha basándose en el crecimiento que presentan sobre su sustrato natural. Es una especie rara en la atmósfera, pero común sobre hojas muertas de diversas especies de vegetales.

\section{BIBLIOGRAFIA}

ARX, J. A. von. 1974. The genera of fungi sporulating in pure culture. J. Gramer, ed. Germany, $315 \mathrm{pp}$.

ELLIS, M. B. 1971. Dematiaceous Hyphomycetes. C.M.I. Kew, 608 pp.

JOLY, P. 1964. Le genre Alternaria. Encycl. Mycol. 33: 1-250.

STALPERS, J. A. 1974. Revision of the genus Oedocephalum (Fungi imperfecti) 1974. Proc. Kon. Ned. Akad. Wet., Ser. C, 77: 383-401. 